\title{
Öğretmen Adaylarının Bilimin Doğası İnanışlarının Tespiti: Bir Ölçek Geliştirme Çalışması ${ }^{1}$ Ișıll ÖZCAN* $\quad$ Halil TURGUT**
}

Öz

Bu çalışmada, fen bilgisi öğretmen adaylarının bilimin doğası inanışlarını belirlenemeye yönelik bir ölçme aracının geliştirilmesi amaçlanmıştır. Bunun için önce ilgili literatürün ve farklı kültürlerde geliştirilmiş ölçme araçlarının ışığında Türkçe düşünülerek bilimin doğasına yönelik bir madde havuzu oluşturulmuştur. Sonra da hem uzmanlardan görüş alınarak hem de bir dizi istatistiksel işlemle söz konusu ölçme arac1nın geçerlik ve güvenirlik analizleri yapılmıştır. İlgili süreçte toplam 364 öğretmen adayının cevapları üzerinden yürütülen işlemler neticesinde geliştirilen ölçme aracının geçerli ve güvenilir sonuçlar üretebilecek yapıda olduğu görülmüştür. Ölçme aracının yapısal analizi sonucunda toplam 37 madde ile yedi farklı alt boyutta bilimin doğası inanışlarının sorgulanabileceği tespit edilmiştir. Söz konusu alt boyutlardan altısında ilgili literatürde yaygın olarak gündeme getirilen değişkenlere odaklanılmış ancak "bilimin kabulleri ve sınırları" biçiminde adlandırılan diğer alt boyutla ölçme sürecine önemli bir katkı yapılmıştır.

Anahtar Kelimeler: Bilimin Doğası, Öğretmen Adayları, Ölçek Geliştirme.

\section{Assessing Preservice Science Teachers' Nature of Science Understanding: A Study of Scale Development}

\begin{abstract}
In this research, the development of an instrument in Turkish for determining the nature of science understandings of preservice science teachers is aimed. For this, firstly an item pool was established by examining the related literature and previously developed instruments. Then the validity and reliability analysis of the developed form were performed with the help of both statistical techniques and expert views. At the end of the analysis process in which the responds of 364 preservice science teachers were utilized, it was concluded that the results yielded by the instrument developed are seen to be valid and reliable. The structural analysis of the instrument showed that it has totally 37 items under seven sub-dimensions. Six of the instrument's determined sub-dimensions are the ones which are commonly discussed in related literature whereas the one called "assumptions and the boundaries" is not. It is assumed that with this subdimension of the instrument, an important contribution to the assessment of nature of science understandings is made.
\end{abstract}

Keywords: Nature of Science, Preservice Science Teachers, Scale Development..

\footnotetext{
${ }^{1}$ Marmara Üniversitesi Eğitim Bilimleri Enstitüsü İlköğretim Anabilim Dalı'nda Halil Turgut danışmanlığında Işıl Özcan tarafından yapılan yüksek lisans tez çalışmasından derlenmiştir.

* Öğretmen, Özbey Ortaokulu, İzmir-Türkiye

** Doç. Dr., Sinop Üniversitesi, halilturgut@sinop.edu.tr
} 


\section{GİRİS}

Günümüz fen ve teknoloji öğretiminin en önemli amaçlarından birisi bilimsel okuryazar bireyler yetiştirmektir (Murcia \& Schibeci, 1999; Tsai, 1999; Abd-El-Khalick \& Lederman, 2000) ve bu anlayış bilginin salt öğretiminden ziyade metodolojik ve epistemolojik değerini de içeren daha üst düzey temalara odaklanmayı gerektirmektedir. Yalnızca bilimsel gerçeklerin, kanunların ve teorilerin aktarımına yönelmiş süreçler kabul görmemekte, bilimsel bilginin neden değerli olduğuna ve neden ona güvenilmesi gerektiğine dair anlayış geliştirilmesi de beklenmektedir. Bu bağlamda fen öğretimi, "zihinsel bağımsızlığı" sağlayan bir değer ve öğrencilere bilginin doğruluğunu başkalarına ihtiyaç duymadan yargılayabilme imkânını verecek kaynakları sağlayan bir süreç olarak tanımlanmaktadır (Munby, 1982).

Yakın geçmişte öğretim programlarında gerçekleştirilen reform çalışmalarıyla birlikte ülkemizde de hâkim olmaya başlayan bu anlayış yukarıda dile getirilen "Bilimsel Okuryazarlık" çatısı altında özellikle "Bilimin Doğası" teması etrafında yoğunlaşmayı kaçınılmaz hale getirmektedir. Önce İlköğretim Fen ve Teknoloji dersi sonra da yeni Fen Bilimleri dersi öğretim programlarında söz konusu temaya atıfta bulunulması, lisans programlarına "Bilimin Doğası ve Bilim Tarihi" gibi bir derslerin konulması ve hem teorik hem de uygulamalı örneklerin Türkçe literatürde yer almaya başlaması bu gerekliliğin kavrandığının önemli göstergelerindendir. Dolayısıyla “Bilimin Doğası"nın, önemli bir ilgi konusu haline geldiği ve artık bireylerin bilimin doğasına dair inanışlarının geliştirilmesinin fen eğitiminin önemli bir bileşeni olarak algılandığı söylenebilir. Çeşitli eğitim reformu girişimleri doğrultusunda birçok ülkenin öğretim programlarında "Bilimin Doğası"nın artık önemli bir eğitsel amaç biçi- minde yer alıyor olması da bu algıya işaret etmektedir (Lederman, 2007).

Diğer yandan, bireylerin bilimin doğası inanışlarının geliştirilmesi amacına odaklanmış araştırmalar, bu yoğun ilgi ve çabaya karşın, farklı yaş gruplarından öğrencilerin ve hatta öğretmenlerin hem yetersiz hem de geçersiz anlayışlar sergilediklerini göstermektedir (Lederman, 1992; Duschl, 1990; Abd-El-Khalick \& Lederman, 2000). Söz konusu başarısızlıkta, bireylerin mevcut bilimin doğası inanışlarını zihinsel anlamda çok iyi özümsemiş olmaları ve bu nedenle de değişime, gelişime karşı direnç göstermeleri önemli sebeplerden birisi olarak ele alınmaktadır (Meichtry, 1992). Bu bakış açısı, bilimin doğası inanışlarının geliştirilmesi sürecinde, dengesizlik yaratarak üzerinde yeniden düşünmelerini sağlayabilmek için öncelikle bireylerin hali hazırdaki anlayışlarının açık edilebilmesi gerektiğini ortaya koymaktadır. Bu durum halen müphem olan bilimin doğası inanışlarının etkili, sağlıklı biçimde belirlenmesi konusunu gündeme getirmektedir (Lederman, Wade \& Bell, 1998; Craven, Hand \& Prain, 2002). Dolayısıyla bir yol haritası oluşturabilmek için öncelikli hedef kitle belirlendikten sonra inanışların açığa çıkartılması ve ölçüme konu edilmesi noktasında bazı sorulara mutlaka cevap verilmelidir.

Hedef kitleyi tanımlarken sonuca etkili biçimde gidebilmek adına bir öncelik sıralaması yapılmalıdır. Süreç içinde asıl amacın öğrencilerin inanışlarının geliştirilmesi olduğu dikkate alındığında ilgi doğal olarak öğrencilere yönelmektedir ancak Çepni, Ayvacı ve Bacanak'ın (2006) da ifade ettiği gibi öğrencilerin bilimin doğası inanışlarının ancak söz konusu alanda inanış geliştirebilmiş öğretmenlerin katkılarıyla daha sağlıklı hale getirilebileceği açıtır. Zira gerekli dokümanlarla takviye yapılsa bile bu yönde yeterlik geliştirememiş öğretmenler 
öğrencilere derin bir anlayış kazandırma şansına sahip olamayacakları gibi birçok boyutta da ciddi yanılgılara sürükleyeceklerdir. Buna bir de mevcut kaynaklardaki naif anlatımlar eklenirse riskin boyutları daha açık biçimde ortaya konulmuş olur. Sonuç olarak öğretmenlerin bilimin doğası bağlamındaki inanışlarının yeterliğinin meselenin önemli bir boyutunu oluşturduğu rahatlıkla söylenebilir. Bu noktada süreci bir adım öncesinden başlatarak dikkatleri öğretmen adaylarına yöneltmek gerekmektedir. Öğretmen adaylarının bilimin doğası inanışlarına odaklanarak bunların belirlenmesiyle ve hangi boyutlarda naif olduklarının tespitiyle onlardan gelecekteki öğrencilerine doğru uzanan bir silsile içinde önemli bir adım atılabilir. $\mathrm{Bu}$ şekilde mevcut genel-geçer kabullerle uyuşmayan naif inanışların dönüştürülmesi adına geliştirilebilecek uygulamalar için de önemli bir alt yapı oluşturulabilir.

“Öncelikle öğretmen adaylarına odaklanılmalıdır" fikrini gerekçesiyle ortaya koyduktan sonra yukarıda da ifade edildiği üzere halen arayışların devam ettiği bilimin doğası inanışlarının açık edilmesi ve değerlendirilmesi hususuna geçilebilir. Bu bağlamdaki girişimler ilgili literatürde önemli ölçüde tartışma konusu yapılmış ve gerek öğrencilere gerekse öğretmen adaylarına ve öğretmenlere odaklanmış ölçme araçları olumlu ve olumsuz yönlerine vurgu yapılarak gözden geçirilmiştir (Craven, Hand \& Prain, 2002). Söz konusu tartı̧maların ülkemizde yürütülen araştırmalar için oluşturduğu anlam ise daha çok hangi ölçme aracının tercih edilerek Türkçeye uyarlanabileceği noktasında düğümlenmektedir. Aslında yerli literatürde bu alanda önemli bir birikim oluşmaya başladığı ve araştırmacıların bilimin doğası inanışlarının tespitinden geliştirilmesine doğru uzanan bir yelpazede uygulamaya dönük öneriler de geliştirmeye başladığ 1 söylenebilir. Mesela Yükseköğretim Kurumu'nun ulusal tez tarama veri tabanında basit bir tarama yapıldığında bile doğrudan bilimin doğası inanışlarına odaklanmış önemli bir tez birikimine ulaşılabilmektedir. Ancak dikkatler inanışların ölçülmesi yani ölçme aracı boyutuna yöneltildiğinde mevcut durumda araştırmaların tipi ne olursa olsun büyük oranda başka dillerde geliştirilmiş araçlara yönelim olduğu ve bunların adaptasyonu yoluna gidildiği görülmektedir. Oysa farklı kültür dairelerinde geliştirilmiş ölçme araçlarının uyarlanması sırasında yaşanılan sıkıntılar inanış belirleme hedefine ulaşılması anlamında bazı olumsuzlukları gündeme getirebilmektedir. Bu yüzden de doğrudan Türkçe düşünerek geliştirilmiş ve bilimin doğası inanışlarını çok boyutlu biçimde sorgulamaya izin verecek bir ölçme aracının yerli literatüre kazandırılması önemli bir ihtiyaç durumundadır.

$\mathrm{Bu}$ araştırmada, söz konusu ihtiyaca cevap verebilmek için, özellikle fen bilgisi öğretmen adaylarını hedef almış kapsamlı bir "Bilimin Doğası İnanışları Ölçeği (BDİÖ)" Türkçe düşünce yapısına da uygun olacak şekilde geliştirilmeye çalışılmıştır. Bunun için önce teorik hazırlık yapılmış ve ilgili literatürde yer alan mevcut ölçme araçlarına kısaca değinilmiştir. $\mathrm{Bu}$ şekilde geliştirilmesi planlanan ölçme arac1nın teorik kurgusu için esas alınan alt boyutlar ortaya konulduktan sonra da oluşturulan formun geçerlik ve güvenirlik değerlendirmesi yapılmıştır.

\subsection{Bilimin Doğası İnanışlarının Tespiti}

Son yıllarda bilimin doğası inanışlarına odaklanmış ölçme araçlarıyla ilgili çalışmalar önemli ölçüde hız kazanmış ve hem nicel hem de nitel bir dizi form geliştirilmiştir (Lederman, AbdEl-Khalick, Bell \& Schwartz, 2002). Bazıları Likert tipi, bazıları da çoktan seçmeli veya açık uçlu sorular üzerine kurgulanmış olan söz konusu ölçme araçları içinde yaygın olarak Likert tipinde olanların tercih edildiği söylenebilir. Geliştirilmelerinin diğer ölçme araçlarına göre daha kolay olması ve kullanışlılıkları 
(Çıttır,2003; Tavşancıl, 2005), geniş kitlelere ulaşma şansı sunmaları, araştırmacı için zaman ve para tasarrufu sağlamaları, değerlendirmede nesnelliğe izin vermeleri vb. hususlar bu yöndeki tercihlerin temel sebepleri arasında sayılabilir. Diğer yandan cevaplarda esnekliğe izin vermemeleri, bireyi sadece ifade edilmiş düşünceler ya da yargılarla sınırlandırmaları ve özgün düşünceleri açıkça ifade etme şansı sunmamaları gibi dezavantajlarının olduğu da bilinmektedir (Balc1, 2001).

Likert tipi ölçme araçlarının söz konusu dezavantajları açık uçlu sorulardan oluşmuş ölçme araçlarını gündeme getirmektedir. Zira bu tür ölçme araçlarıyla düşünceler daha derinlemesine irdelenebilmekte, bireyler belli şılara bağlı kalmadan kendilerini özgün biçimde ifade edebilmektedir. Ancak bu sefer de ölçmede standardın sağlanmasındaki güçlük ve sayının sınırlı tutulmak zorunda olması gibi dezavantajlar gündeme gelmektedir. Bir de yukar1da bahsedilen iki türle de tam olarak uyuşmayan ve bunların dışında değerlendirilebilecek bazı ölçme araçlarından bahsedilebilir ki Aikenhead ve Ryan (1992) tarafından geliştirilen "Views on Science-Technology-Society" (VOSTS) bu kategoridedir. VOSTS'da yer alan her bir soru ilgili konuda görüş bildiren bir cümle ile başlar ve katılımcılar kendilerine sunulan seçenekleri değerlendirerek yine kendi düşünceleri doğrultusunda tercihte bulunurlar. VOSTS'un deneysel olarak geliştirildiği yani daha önce yürütülmüş araştırmalarda açı̆̆a çıkartılmış düşünceler üzerine kurgulandığ 1 iddiası (Aikenhead \& Ryan, 1992) ile birlikte biçimi onun da kendi içindeki muhtemel avantaj ve dezavantajları hakkında fikir vermektedir.

Tüm bu tartışmalar inanışları ve özellikle bilimin doğası gibi kendi içinde çok farklı görüşler ve felsefi tartışmalar barındıran bir alana dair inanışları sağlıklı biçimde açığa çıkartabilmenin (geride hiç soru işareti bırakmayacak şekilde) çok zor olduğunu göstermektedir. Neredeyse 1950'lilerden beri süregelen, ya bilimle ya da bir yönüyle bilimin doğasıyla ilgili inanışların sorgulandığı ölçme araçlarının geliştirilmesi yönündeki çabalar da buna işaret etmektedir. Söz konusu çabalardaki süreklilik ve arayışın devamlılığı, daha önce geliştirilmiş ölçme araçlarının ana hatlarıyla gözden geçirildiği bir araştırmada Lederman (2007) tarafından açıkça ortaya konmuştur. Araştırmacının oluşturduğu uzun listede, Likert tipinden açık uçlu sorulardan oluşmuş formlara kadar uzanan bir yelpazede, biraz da ölçme işleminin yapılacağı grubun özellikleri ve büyüklüğüne göre tercih konusu olabilecek birçok araç yer almıştır. Ancak yine listede görüldüğü üzere hepsi de farklı kültürel dokular ve duyarlılıklar ışı̆̆ında geliştirilmiştir ve Türkiye şartlarında kullanılabilmeleri için kültürel duyarlılığın da dikkate alınacağı süreçlerde adapte edilmeleri gerekmektedir. Ayrıca söz konusu adaptasyon işleminden önce bilimin doğası bağlamında alt boyutların, bileşenlerin (güncel literatür ışığında) neler olması gerektiği ve ilgili ölçme araçlarının böyle bir gerekliliği etkili biçimde karşılayıp karşılayamadığı mutlaka değerlendirilmelidir. Tüm bu hususlar böyle bir listeye güncel literatür ışığında doğrudan Türkçe olarak geliştirilmiş ölçme araçlarının eklenmesiyle önemli bir ihtiyaca cevap verilebileceğini ve kullanımda önemli bir pratiklik sağlanabileceğini göstermektedir.

Bu noktada atılması gereken ilk adım ise ölçme aracının türüne karar verilmesi olacaktır ki bunun için geliştirilmesi planlanan ölçme aracının kullanım sürecine ve biçimine odaklanılması gerekir. Bu araştırmada esas alınan amaç geniş kitlelere kolayca uygulanabilecek ve elde edilen verilerin değerlendirilebilmesi için ciddi bir uzmanlık gerektirmeyecek dolayısıla uygulama açısından kullanışlılık ve pratiklik ölçütlerini karşılayacak bir ölçme aracı gelişti- 
rebilmek olduğu için yukarıda da ortaya konulan tartışmalar 1şığında Likert tipinde karar kılınmıştır. Ölçme aracının türünü bu şekilde belirledikten sonra da bilimin doğası başlığı altında yer alması gereken alt boyutların sağlıklı biçimde ortaya konulabilmesi için bir değerlendirme yapılmıştır.

\subsection{Bilimin Doğası İnanışlarının Alt Boyutları}

Bilimin doğası başlığı altında yer verilebilecek alt boyutları tartışmasız biçimde sıralayabilmek mümkün olmasa da öğretime konu edilebilecek olanlar üzerinde bir uzlaşmanın sağlandığı ve bu uzlaşma üzerinden bir açılıma gidildiği görülmektedir. Bu tür bir açllımda ilk planda;(i)bilimsel bilginin değişimi, (ii)gözlemçıkarım ayrımı, (iii)bilimsel yöntem/yöntemler (iv)yaratıcilik-hayal gücü, (v)sosyo-kültürel etki ve (vi)teoriler-kanunlar gibi başlıklarla ele alınabilecek alt boyutlara yer verilmektedir. Mevcut fen eğitimi reformu raporlarında da açıkça atıf yapılan bu alt boyutlar üzerinde başka birçok araştırmacı da büyük oranda hemfikirdir (örn. McComas, Clough \& Almazroa, 2000; Lederman, Abd-El-Khalick, Bell \& Schwartz, 2002; Lederman 2007). Diğer yandan bireylerin bilim algılarının tam olarak genel kabule konu olmuş görünen bu alt boyutlar üzerinden ortaya konulup konulamayacağ 1 tartışmalıdır. Zira literatürde yaygın olarak görülen bu ve benzeri açlımlarda bilimin doğası teması salt bilimsel bilginin doğası (bkz. Lederman, 2007) biçiminde bilimsel bilginin mahiyeti ve üretimi bağlamında özelleştirilse bile modern bilimin metafizik çekirdeğinden (Dilworth, 2006) hareketle bilimin sinurlarına ve üzerine bilgi inşa ettiğimiz kabullerine açıkça değinilmemektedir ki bu önemli bir eksiklik olarak değerlendirilebilir. Bu yüzden araştırmanın bundan sonraki bölümlerinde üzerinde uzlaşma sağlandığı düşünülen bileşenlerle birlikte söz konusu metafizik kabullere de ayrı bir başlık açılarak bilimin doğası inanışlarının çerçevesi daha geniş bir kapsamda çizilmeye çalışılmıştır.

(i)Bilimsel Bilginin Değişimi: Bilimsel bilgi statik, bütün ve "mutlak" değildir (Abd-El Khalick, 2001). Bilimsel bilginin güvenilir ve uzun süreli olduğu söylenebilir, fakat mutlak doğruluğundan ya da kesinliğinden bahsedilemez. Bilimsel bilgi yeni verilerin elde edilmesi, var olan verilerin farklı biçimde yorumlanması veya teknolojik gelişmelerin sağladığı yeni birtakım avantajlar neticesinde değişime uğrayabilir (AAAS, 1993). Değişimin evrimsel (Popper, 1998) veya devrimsel (Kuhn, 1970) biçimlerde gerçekleşebileceği ileri sürülmektedir.

(ii)Gözlem-Çıkarım Ayrımı: Bilim hem gözleme hem de bu gözlemler üzerinden yapılan çıkarımlara dayanır. Gözlemler duyular ya da çeşitli araçlar yardımıyla elde edilebilen veriler sağlarken çıkarımlar yoluyla bu veriler üzerinden gözlenen olayların nedenleri açıklanır ve yorumlanır (Lederman, Abd-El-Khalick, Bell \& Schwartz, 2002). Mesela serbest birakılan bir cismin yere doğru düşmesi gözlemlenir ve yerçekimi kuvveti nedeniyle düştügüne dair çıkarımda bulunulur (Lederman, 2002; Lederman, 2007).

(iii)Bilimsel Yöntem/Yöntemler: Gerçekte bilimin karmaşık yapısıyla uyuşan evrensel bir yöntemden söz etmek imkânsızdır (Abd-El Khalick, 2001) ve bilim adamlarının araştırmaları sırasında adım adım takip ettikleri tek ve evrensel bir yöntemden bahsetmek mümkün değildir (AAAS, 1990; McComas, 1998). Farklı bilim dallarında farklı yöntemler, metodolojiler esas alınmakta ve bu yöntemler zamanla değişime uğrayabilmektedir (Chalmers, 1999).

(iv) Yaratıcılık ve Hayal Gücü: Bilimin ürünleri, konu edindiği gerçeği aslına tam olarak uygun bir şekilde temsil etmekten çok gözlemlere, deneylere ve çıkarımlara ek olarak yaratıcılık 
ve hayal gücünün de katkısıyla yansıtma iddiası taşır (Lederman, Abd-El-Khalick, Bell \& Schwartz, 2002; Lederman, 2007). Bilimsel bilginin üretilmesi, gelişmesi doğanın gözlenmesinin yanında insan hayali ve yaratıcılığını da içerir ve yaratıcılığın bilimde önemli bir yeri vardır (Abd-el Khalick, 2001). Bilimsel bilginin bu yönü onun çıkarımsal doğası ile de ilişkilidir. Mesela atomlar, kara delikler vb. teorik modellerde hayal gücü ve yaratıcılığın önemli payı vardır (Lederman, 2007).

(v)Sosyo-Kültürel Etki: Bilim, insani bir etkinliktir ve bilimsel fikirler de içinde yeşerdiği sosyal ve tarihi iklimden etkilenir (AAAS, 1993). Bilim insanlarının teorik ve disiplinlerine olan bağımlılıkları, inançları, öncül bilgileri, eğitimleri, tecrübeleri, beklentileri, milliyetleri, cinsiyetleri ve yaşları gibi etkenler yaptıkları çalışmaları çeşitli şekillerde biçimlendirir (AAAS, 1990; McComas, 1998; Lederman, 1998; Chalmers, 1999). Bütün bu etkenler bilim insanlarının çalışmalarını nasıl kurguladıklarını, neyi gözlemleyeceklerini, gözlemlerini nasıl yorumlayacaklarını etkileyen bir zihin yapısı oluştururlar. Dolayısıyla bilim insanları içinde yetiştikleri ve şekillendikleri toplumdan, kültürden, disiplin alanından ve aldıkları eğitimin onlara kazandırdığı anlayıştan büyük oranda etkilenirken bu etkiyi bilimsel faaliyetlerine de taşırlar.

(vi)Bilimsel Kanun ve Teoriler: Teoriler ve kanunlar bilginin farklı türleridir (McComas, 1998). Teoriler bilimsel olguları açıklamak, tanımlamak ve bazı kestirimlerde bulunmak için kullanılan araçlardır ve genellikle belirli varsayımlara ve gözlemlenemeyen varlıklara dayanırlar. Bu yüzden de doğrudan test edilemezler ve ancak dolaylı yoldan toplanan kanitlarla desteklenerek geçerliliklerini sürdürürler; bilim insanları teorilerden test edilebilir tahminler çıkartarak bu tahminleri sınama konusu yaparlar. Kanunlarsa doğal varlıklar ve olaylar arasındaki gözlemlenebilir ilişkilerin betimsel ifadeleridir (Palmquist \& Finley, 1997; Brown, Luft, Roehring \& Kern, 2006). Teoriler ve kanunlar birbirlerine dönüşmezler.

(vii)Bilimin Kabulleri ve Sinırları: Bilim, alan ve yöntem/yöntemler açısından kapsamı, sınırları tartışmasız biçimde belirli bir etkinlik değildir ve çok yönlü, bazı durumlarda sınırları belirsiz, karmaşık bir oluşumdur. Dolayısıyla sınırlarını ifşa eden kesin bir tanımından bahsedilemez, ancak onun da diğer bütün bilme biçimleri gibi açık veya örtük bir takım temel inanç ve varsayımlara dayandığı söylenebilir. Bizim dışımızda bir olgular dünyası vardır ve bu dünya anlaşılabilirdir gibi yargılar bu anlamda örneklerdir (Yıldırım, 2007). Benzeri varsayımları kapsayan bir değerlendirme ile gerçeklik, düzenlilik, bilinebilirlik ve illiyet (sebep-sonuç ilişkisi) gibi başlıklar altında daha sistematik bir açılım da yapılabilir (Hocaoğlu, 1996). Dolayısıyla bilimin nasıl bir bilme eylemi, biçimi olduğunu anlayabilmek ve sınırları hakkında fikir sahibi olabilmek için üzerine kurgulandığı (gerek epistemolojik gerekse ontolojik) kabul ve varsayımlara daha yakından bakmak gerekmektedir. Bu anlamda Hocaoğlu (1996), Gauch (2009) ve Dilworth (2006) gibi araştırmacıların eserleri inceleme konusu yapılabilir.

Biçimine (Likert tipi) karar verdikten ve teorik çerçevesini ortaya koyan, bilimin doğası başlı̆̆ı altında mutlaka yer verilmesi gereken temel alt boyutlara bu şekilde değindikten sonra geliştirilmesi planlanan ölçme aracinın maddeler bazında oluşturulmaya başlanması işlemine geçilmiş, araştırmanın bundan sonraki bölümünde söz konusu süreç ortaya konmuştur.

\section{YÖNTEM}

Bu bölümde Bilimin Doğası İnanışları Ölçeğinin (BDİÖ) geliştirilmesine ilişkin süreç adımlar halinde ortaya konmuş ve sırasıyla "madde havuzunun oluşturulması ve pilot uygulama ile gecelik ve güvenirlik analizi" işlemleri ele alınmıştır. 


\subsection{Madde Havuzunun Oluşturulması ve Pilot Uygulama}

Geliştirilen “Bilimin Doğası İnanışları Ölçeği (BDİÖ)"için oluşturulan madde havuzunun ilk planda yukarıda ifade edildiği gibi bilimin doğası başlığı altında gözden geçirilen alt boyutlar üzerinden çerçevesi çizilen teorik yapıyı yansıtacak nitelikte olmasına özellikle dikkat edilmiştir. Bu doğrultuda bazı maddeler başka araştırmacılar tarafından benzer konularda hazırlanan ölçme araçlarının (Rubba \& Andersen, 1978; Aikenhead \& Ryan 1992; Lederman, Abd-El-Khalick, Bell \& Schwartz, 2002; Muşlu, 2008; Can, 2008) içeriği örnek alınarak bazıları da özgün biçimde araştırmacılar tarafından hazırlanmıştır. Bu aşamada yanlış anlaşılmaları mümkün olduğunca alt düzeye indirgeyebilmek için kullanılan lisanın sade olmasına, kelimelerin dizilişinin ve cümlelerin kuruluşunun açık olmasına özen gösterilmiştir. Oluşturulan ilk havuzda bu tür nitelikleri sağladığına inanılan 49 madde yer almış ve yanıtlayıcıyı olumlu ya da olumsuz yanitlamaya yönlendirici etki yapma olasılığını düşürebilmek adına söz konusu maddeler olumlu ve olumsuz ifadeler şeklinde karışık olarak sıralanmıştır.

Madde havuzunda yer alması planlanan maddeler bu şekilde yapılandırıldıktan sonra uzman görüşüne başvurularak hem kapsam geçerliliği hem de dil, anlatım ve biçim açısından değerlendirilmiştir. $\mathrm{Bu}$ safhada üç öğretim üyesinin ve bir fen bilgisi öğretmenin görüşleri doğrultusunda maddelerin bir kısmı düzeltilmiş, bir kısmının ise çıkarılmasına karar verilmiştir. Mesela "Bilimsel modeller gerçeğin kopyalarıdır" maddesi, bilimsel model kavra- minı bazıları basit maketler (insan vücudu maketi gibi) bazıları ise görselleştirilmiş teorik yapılar (DNA ve atom modeli gibi) şeklinde algılayabilir düşüncesiyle uzman tavsiyesi doğrultusunda havuzdan çıkarılmıştır. Çıkarılanlar ve değiştirilenlerden sonra kalan 42 madde ile oluşturulan BDİÖ'nün ilk formu dil ve anlatım açısından sorun olup olmadığının görülebilmesi için küçük bir grupla (47 öğretmen adayı) yapılacak pilot uygulama için hazır hale getirilmiştir. Söz konusu pilot uygulamada katılımcılara maddelerde anlamadıkları veya yanıtlamakta zorlandıkları yerler olup olmadı$\breve{g}_{1}$ sorularak ilgili geri bildirimler alınmış ve bu şekilde BDİÖ geçerlik ve güvenirlik analizi için gerekli verilerin toplanacağı asıl uygulamaya hazır hale getirilmiştir.

2.2 BDİÖ’nün Geçerlik ve Güvenirlik Analizleri

BDİÖ'nün pilot uygulamadan sonraki hali İstanbul ilindeki iki devlet üniversitesinin fen bilgisi öğretmenliği anabilim dallarında öğrenim görmekte olan farklı sınıf düzeylerinden 390 öğretmen adayına uygulanmıştır. Söz konusu devlet üniversiteleri uygulamanın sağlıklı yürütülebilmesi adına doğrudan ulaşılabilirlik esasınca belirlenmiştir. Ancak geçerlik ve güvenirlik analizleri, uygulamaya sağlıklı biçimde katılmayanlar (formun bir kısmını cevaplandirmayan ve rastgele cevaplandiranlar) gruptan çıkartıldıktan sonra kalan 364 öğretmen adayının sağladığı veriler üzerinde yapılmıştır. Araştırmanın çalışma grubunda yer alan adayların sınıf düzeylerine göre dağılımları aşağıda Tablo 1'de sunulmuştur.

Tablo 1. Adayların Sınıf Düzeylerine Göre Frekans ve Yüzde Dağılımları

\begin{tabular}{ccc}
\hline Sinıf Düzeyleri & f & \% \\
\hline 1 & 120 & 32,96 \\
2 & 75 & 20,60 \\
3 & 85 & 23,35 \\
4 & 84 & 23,07 \\
Toplam & 364 & 100,0 \\
\hline
\end{tabular}


Çalışmada yer alan adayların BDÏÖ’de yer alan maddelere verdikleri cevaplara, ölçme aracının doğası gereği, 1'den 5'e değişen puanlar atanmıştır. İlgili literatürde genel kabul gördüğü ortaya konulmuş olan inanışlara muhalif olarak yapılandırılmış maddelerde ise söz konusu puanlama tersten yapılmıştır. Adayların BDÏÖ'de yer alan maddelere verdikleri cevaplar bu şekilde puanlandırıldıktan sonra geçerlik ve güvenirlik analizinde ilk adım geçerlik adına atılmış ve bu kapsamda ölçme aracında yer alan maddelerin kapsam ve yapı geçerliği (katılımcıların sağladığı veriler bağlamında) sorgulanmıştır. Kapsam geçerliliği için ilgili konu alanında uzman 3 akademisyenden görüş istenmiş ve madde havuzunun oluşturulması ile pilot uygulama başlı̆̆ı altında da ifade edildiği gibi bazı maddeler için gerekli görülen değişiklikler yapılarak ölçme aracı söz konusu geçerlik anlamında iyileştirilmiştir. Kapsam geçerliği ile ilgili işlemler tamamlanıp gerekli uygulama yapıldıktan sonra ölçme aracının yapı geçerliği değerlendirilmiş ve bunun için de ölçme aracında yer alan maddelerin aynı ya da yakın nitelikleri ölçüp-ölçmediğini veya farklı boyutlar altında toplanıp toplanmadığını saptamak üzere "faktör analizi" yapılmıştır (Karasar, 2002; Büyüköztürk, 2010). Söz konusu süreçte önce BDİÖ'nün uygulandığı örneklem büyüklüğünün faktör analizi için uygun olup olmad1$\breve{g} 1$ sorgulamış bunun için de Kaiser-MeyerOlkin (KMO) ve Bartlett Testi değerleri hesaplanmıştır. Elde edilen KMO ve Bartlett Testi değerleri aşağıda Tablo 2'de sunulmuştur.

Tablo 2. KMO ve Bartlett Testi Sonuçları

\begin{tabular}{lcc}
\hline \multicolumn{2}{l}{ Kaiser-Meyer-Olkin (KMO) } & 0,74 \\
\multicolumn{2}{l}{ Örneklem Ölçüm Değer Yeterliği } & 4091,37 \\
Bartlett Testi & Ki-Kare Değeri & 666 \\
& $\mathrm{Sd}$ & 0,00 \\
\hline
\end{tabular}

Tablo 2'de sunulan KMO (0,60 ve üzerinde olması gerekmektedir, bkz. Akgül ve Çevik, 2003; Büyüköztürk, 2010) ve Bartlett Testi değerleri (anlamlı bulunmuştur) verilerin faktör analizi için uygun olduğunu göstermiştir. Bu yargıya ulaştıktan sonra, geliştirilen ölçme aracı için oluşturulan maddeler 7 alt boyutta belirli bir kuramsal çerçeveye göre hazırlandığı için (daha önce ilgili bölümde ele alınmışt1) "doğrulayıcı faktör analizi" yapılmıştır. Toplamda 7 faktör ile sınırlandırılarak gerçekleştirilen söz konusu analiz sürecince her bir faktörün hesaplanan özdeğeri, varyans ve toplam varyans yüzdesi aşağıda Tablo 3’te sunulmuştur.

Tablo 3. Faktörlerin Özdeğer, Varyans ve Toplam Varyans Yüzdeleri

\begin{tabular}{|c|c|c|c|}
\hline Faktör & Özdeğer & Varyans Yüzdesi & Toplam Varyans Yüzdesi \\
\hline 1 & 5,03 & 13,59 & 13,59 \\
\hline 2 & 3,31 & 8,95 & 22,54 \\
\hline 3 & 2,65 & 7,16 & 29,70 \\
\hline 4 & 2,17 & 5,85 & 35,55 \\
\hline 5 & 2,01 & 5,44 & 40,99 \\
\hline 6 & 1,75 & 4,73 & 45,72 \\
\hline 7 & 1,64 & 4,43 & 50,15 \\
\hline
\end{tabular}


Tablo 3'te sunulan değerler, bütün faktörlerin özdeğerlerinin 1'den büyük olduğunu ve yedi faktörün toplam varyansın \% 50,15'ini açıkladığını (\% 40 ile \% 60 arası değerlerde faktör yapısı güçlü kabul edilir, bkz. Tavşancıl, 2005), dolayısıyla ölçme aracının bu 7 faktör üzerinden değerlendirilebileceğini göstermiştir. Analizin devaminda hangi maddelerin hangi faktör altında yer aldığına karar verebilmek için ise temel bileşenler analizi (varimax rotasyonu) ile ulaşılan veriler yük değerleri esas alınarak değerlendirilmiştir. Bu şekilde yük değerleri 0,30'un üstünde olan (Büyüköztürk, 2010) ve birden fazla faktörün altında yer alması söz konusu ise yük değeri farkı 0,10'dan büyük olan (Tezbaşaran, 1996) 37 madde 7 faktör altında gruplandırılmıştır. BDİÖ bünyesinde kalan söz konusu 37 madde yeniden numaralandırılmış (bkz. ek) ve ilgili faktörlere (alt boyutlara) dağılımları faktör isimleri ve yük değerleriyle birlikte aşağıda Tablo 4'te sunulmuştur.

Tablo 4. BDİÖ Faktör Analizi Sonuçları

\begin{tabular}{lcc}
\hline \multicolumn{1}{c}{ Faktörler } & Maddeler & Yük Değerleri \\
\hline Bilimsel Bilginin Değişimi & $1,8,15,20,23,30$ & $0,543-0,779$ \\
Gözlem ve Çıkarım & $2,13,21,25$ & $0,688-0,741$ \\
Bilimsel Yöntem/Yöntemler & $3,19,29,32$ & $0,761-0,818$ \\
Yaratıcılık ve Hayal Gücü & $4,9,17,24,37$ & $0,337-0,737$ \\
Bilimin Kabulleri ve Sınırları & $5,7,16,22,26,28,34,36$ & $0,413-0,704$ \\
Sosyo-kültürel Etki & $6,12,18,33$ & $0,605-0,746$ \\
Bilimsel Kanun ve Teoriler & $10,11,14,27,31,35$ & $0,395-0,649$ \\
\hline
\end{tabular}

Tablo 4'te sunulan değerler ölçme aracında bırakılan 37 maddenin faktör yük değerlerinin 0,337 ile 0,818 arasında değiştiğini göstermiştir. Tabloda yer alan faktörler, bu faktörler altında gruplanan maddelerin temaları ve bilimin doğası başlığı altında konu edindikleri kavramlar değerlendirilerek adlandırılmıştır. Bu aşamada söz konusu maddelerin yazımı aşamasında esas alınan teorik çerçeve (araştırmanın giriş bölümünde sunulmuştu) de dikkate alınmıştır. Mesela 10., 11., 14., 27., 31. ve 35. maddelerin altında gruplandığı kategori, bu maddeler ya kanunları ya teorileri ya da ikisi arasındaki ilişkiyi/farklılığı konu edindiği için ilgili literatürde de yer aldığı üzere (bilimin doğası başlı̆̆ı altında doğrudan bir alt boyut olarak gündeme getirilir) "bilimsel kanun ve teoriler" biçiminde adlandırılmıştır.

BDİÖ'nün geçerlik değerlendirmesi tamamlandiktan ve yapısal anlamda alt boyutları da belirlendikten sonra güvenirliği (ilgili faktörler 1şı̆̆ında) inceleme konusu yapılmıştır. Söz konusu süreçte iç tutarlık güvenirliği için Madde-Toplam korelasyon katsayıları ve Cronbach Alfa değerleri hesaplanmıştır (Balcı, 2001; Ergin, 1995). Ulaşılan katsayılar ve değerler, BDİÖ'nün faktörlerine (alt boyutlarına) göre aşağıda Tablo 5'de sunulmuştur. 
Tablo 5. BDİÖ Madde Toplam Korelâsyon Katsayıları ve Cronbach Alfa Değerleri

\begin{tabular}{|c|c|c|c|c|}
\hline Faktörler & Maddeler & $\mathrm{r}$ & $p$ & $\alpha$ \\
\hline \multirow{6}{*}{ Bilimsel Bilginin Değişimi } & 1 & 0,765 & 0,000 & \multirow{6}{*}{0,803} \\
\hline & 8 & 0,597 & 0,000 & \\
\hline & 15 & 0,330 & 0,000 & \\
\hline & 20 & 0,394 & 0,000 & \\
\hline & 23 & 0,454 & 0,000 & \\
\hline & 30 & 0,574 & 0,000 & \\
\hline \multirow{4}{*}{ Gözlem ve Çıkarım } & 2 & 0,613 & 0,000 & \multirow{4}{*}{0,704} \\
\hline & 13 & 0,528 & 0,000 & \\
\hline & 21 & 0,690 & 0,000 & \\
\hline & 25 & 0,510 & 0,000 & \\
\hline \multirow{4}{*}{ Bilimsel Yöntem } & 3 & 0,676 & 0,000 & \multirow{4}{*}{0,829} \\
\hline & 19 & 0,380 & 0,000 & \\
\hline & 29 & 0,570 & 0,000 & \\
\hline & 32 & 0,626 & 0,000 & \\
\hline \multirow{5}{*}{ Yaratıcılık ve Hayal Gücü } & 4 & 0,434 & 0,000 & \multirow{5}{*}{0,705} \\
\hline & 9 & 0,370 & 0,000 & \\
\hline & 17 & 0,678 & 0,000 & \\
\hline & 24 & 0,596 & 0,000 & \\
\hline & 37 & 0,757 & 0,000 & \\
\hline \multirow{8}{*}{ Bilimin Kabulleri ve Sınırları } & 5 & 0,550 & 0,000 & \multirow{8}{*}{0,764} \\
\hline & 7 & 0,537 & 0,000 & \\
\hline & 16 & 0,659 & 0,000 & \\
\hline & 22 & 0,398 & 0,000 & \\
\hline & 26 & 0,403 & 0,000 & \\
\hline & 28 & 0,407 & 0,000 & \\
\hline & 34 & 0,584 & 0,000 & \\
\hline & 36 & 0,690 & 0,000 & \\
\hline \multirow{4}{*}{ Sosyo -Kültürel Etki } & 6 & 0,855 & 0,000 & \multirow{4}{*}{0,732} \\
\hline & 12 & 0,696 & 0,000 & \\
\hline & 18 & 0,876 & 0,000 & \\
\hline & 33 & 0,597 & 0,000 & \\
\hline \multirow{6}{*}{ Bilimsel Kanun ve Teoriler } & 10 & 0,775 & 0,000 & \multirow{6}{*}{0,702} \\
\hline & 11 & 0,349 & 0,000 & \\
\hline & 14 & 0,564 & 0,000 & \\
\hline & 27 & 0,422 & 0,000 & \\
\hline & 31 & 0,389 & 0,000 & \\
\hline & 35 & 0,405 & 0,000 & \\
\hline
\end{tabular}

Tablo 5'de sunulan sonuçlar hem MaddeToplam korelasyonları hem de Cronbach Alfa değerlerinin (tümü için 0,783) ölçme aracının tüm faktörleri (alt boyutları) için anlamlı ve kabul edilebilir düzeyde olduğunu dolayısıyla ölçme aracının iç tutarlığı anlamındaki güve- nirliğine dair olumlu kanı oluşturulabileceğini göstermiştir.

\section{TARTIŞMA ve SONUÇ}

Geliştirilmesi fen eğitiminin öncelikli amaçlarından birisi olarak görülen bilimin doğası inanışları, bireyler için sağlıklı bir dünya görü- 
şü oluşturmaları anlamında da hayati öneme sahiptir. Zira birçok kaynaktan edindiği bilgi iddialarını algilayabilen, yorumlayabilen, değerlendirebilen ve eleştirel anlamda sorgulayabilen bireyler demokratik toplumun karar alma mekanizmalarına sağlıklı bir şekilde dâhil olabileceklerdir. Ancak tüm bu gerekçelerin ve benzerlerinin tartışmasız biçimde gündemin ilgi çekici bir bileşeni haline getirdiği bilimin doğası inanışlarının süreç içerisinde önce tanımlanması sonra tespit edilmesi ve geliştirilmesi anlamında halen atılması gereken önemli adımlar olduğu da bir gerçektir (Turgut, 2010). İlgili literatüre bakıldığında bilimin doğası başlığı altında ele alınabilecek inanış, kavram ve değerler noktasında belirli düzeyde bir uzlaşmaya varıldığı söylenebilir (Turgut, 2011). Söz konusu uzlaşma bilimin doğası inanışlarının ölçümünde odaklanılacak alt boyutlar hakkında önemli fikirler vermektedir.

$\mathrm{Bu}$ araştırmada geliştirilen ölçme aracıyla bu anlamda üzerinde uzlaşı sağlanmış alt boyutlar bağlamında bilimin doğası inanışlarını kapsamlı biçimde sorgulamaya izin verecek bir yapı geliştirildiği görülmüştür. Yapılan değerlendirmeler, özellikle mevcut ölçme araçlarında yaygın biçimde gözlenmeyen (bkz. Lederman, 2007) "Bilimin Kabulleri ve Sınırları" gibi bir alt boyutu da içeren geçerli ve güvenilir bir aracın geliştirildiğini ortaya koymuştur. Yerli literatürde geniş kitlelere uygulanabilecek Likert Tipi ve Türkçe geliştirilmiş kapsamlı ölçme araçlarına halen ihtiyaç duyulduğu dikkate alınırsa bu aracın önemi daha kolay anlaşılabilir. Zira benzer bağlamlar için farklı kitlelere dönük Türkçe geliştirilmiş ölçme araçlarının varlığı bir gerçektir ancak bu araçların kapsam olarak bilimin doğasını bütünüyle kucaklayıp kucaklamadığı tartışma konusudur. Mesela sadece bilimsel bilgiye ve epistemolojik inanışlara odaklanmış araçlarla (bkz. Çoban ve Ergin, 2008) bilimin doğası inanışlarını bütünüyle ölçmek mümkün olmayacaktır.
Aslında Türkçe düşünerek geliştirilmiş ve geniş kitlelere uygulanabilecek kapsamlı bir bilimin doğası inanışları ölçeğine duyulan ihtiyaç Türkiye'de yürütülen bilimin doğası konulu tez çalışmalarında da açıkça görülmektedir. Zira bu çalışmalarda kullanılan ölçme araçlarının neredeyse tamamı farklı dillerden çevirisi veya adaptasyonu yapılmış ölçme araçları ile yürütülmüştür ve büyük oranda yapılandırılmış bir formata sahip VOSTS (Aikenhead \& Ryan, 1992) ile açı uçlu VNOS (Lederman, Abd-ElKhalick, Bell, Schwartz, 2002) tercih edilmiştir. Ancak Türkçeye kazandırılmış ve birçok çalışmada kullanılmış bu araçların geniş kitlelere uygulanma şansı çok yoktur ve analiz süreçleri uzmanlık gerektirmektedir. Bu anlamda, bu araştırma sürecinde geliştirilen ve yapılan değerlendirmeler neticesince geçerliği ve güvenirliği hususunda olumlu verilere ulaşılmış olan likert tipindeki BDïÖ hem bilimin doğasını geniş kapsamlı ölçme hem de geniş kitlelere ulaşma şansı vermesi açısından önemli bir ihtiyacı karşılayacaktır. Dolayısıyla, BDİÖ'nün Türkçe düşünerek hazırlanmış olması, kültürel duyarlılığın sağlanması ve ilgili literatürde yer alan Türkçeye uyarlanmış olsun ya da olmasın birçok ölçme aracında bir alt boyut biçiminde açıkça yer almamış "Bilimin Kabulleri ve Sınırları" gibi bir bileşeni içermesi önemlidir. Diğer yandan bütün Likert tipi ölçme araçları için ifade edilebilecek sınırlılıkları BDİÖ açısından da dikkate almakta yarar vardır.

\section{4. ÖNERILER}

$\mathrm{Bu}$ araştırmada geliştirilen ölçme aracının likert tipi olması nedeniyle doğasında barındırdığı sınırlılıklar bilimin doğası inanışlarını ölçmeye yönelik araç geliştirme çalışmalarının koordineli biçimde devam ettirilmesi gerektiğini göstermektedir. Zira geniş kesimlere ulaşma şansı verecek bu tür likert tipi araçların geliştirilmesiyle atılan adımlar devaminda derinlikli değerlendirme şansı verecek açık uçlu araçların 
geliştirilmesi yoluyla pekiştirilmelidir. Aslında yapılması gereken birkaç aşamalı, bütüncül bir ölçme süreci planlamak ve bu şekilde hem genel profili görmek hem de bu profil üzerinden belirlenecek temsil gücü yüksek küçük gruplarla inanışların arka planında yatan gerekçelerin derinlemesine analizine yönelmek olmalıdır. Geçerlik ve güvenirlik analizleri BDİÖ'nün bu birkaç aşamalı süreçte ilk basamakta yani büyük gruplarda genel profili sağlıklı bir şekilde ortaya koyabilme noktasında gerekli misyonu üstlenebileceğini göstermektedir. Ancak faktör yapısıyla dolayısıyla alt boyutlarıyla bilimin doğası inanışlarını kapsamlı biçimde belirleyebilme şansını sunacak BDIÖÓnün ikinci basamakta büyük gruptan seçilecek bireylerle derinlemesine yapılacak bir sorgulama için açık uçlu bir formla desteklenmesi yerinde olacaktır. Bunun için yine BDÏÖ'nün alt boyutları üzerinden geliştirilecek bir mülakat formu müteakip araştırmaların konusu yapılabilir.

\section{Kaynakça}

Abd-El-Khalick, F. \& Lederman, N.G.(2000). Improving Science Teachers' Conceptions of Nature of Science: A Critical Review of the Literature. International Journal of Science Education, 22(7), 665701.

Abd-El-Khalick, F.(2001). Embedding Nature of Science in Preservice Elementary Science Courses: Abandoning Scientism, But... Journal of Science Teacher Education, 12(3), 215-233.

Aikenhead, G.S.\& Ryan, A.G.(1992). The Development of a New Instrument: "Views on ScienceTechnology-Society" (VOSTS). Science Education, 76(5), 477-491.

Akgül, A. \& Çevik, O.(2003). İstatistiksel Analiz Teknikleri.Ankara: Emek Ofset Baskı.

American Association for the Advancement of Science [AAAS](1990). Science for All Americans. New York: Oxford University Press.

American Association for the Advancement of Science [AAAS](1993). Benchmarks for Science Literacy: A Project 2061 Report. New York: Oxford University Press.

Balcı, A.(2001). Sosyal Bilimlerde Araştırma Yöntem, Teknik ve Ilkeleri (5. bask1). Ankara: Pegema Yayınevi.

Brown, M., Luft, J., Roehring, G. \& Kern, A.(2006). Beginning Science Teachers' Perspectives on the Nature of Science: The Development of a Nature of Science Rubric. The ASTE 2006 InternationalConference. Portland, Oregon.

Büyüköztürk, Ş.(2010). Veri Analizi El Kitabı (11 Baskı). Ankara: Pegema Yayıncılık.

Can, B.(2008). İlköğretim Öğrencilerinin Bilimin Doğası İle İlgili Anlayışlarını Etkileyen Faktörler. Yayınlanmış Doktora Tezi, Dokuz Eylül Üniversitesi Eğitim Bilimleri Enstitüsü.

Chalmers, A.F.(1999). What Is This Thing Called Science? (3rd ed.). Buckingham: Open University Press.

Craven, J.A., Hand, B. \& Prain, V.(2002). Assessing Explicit and Tacit Conceptions of the NOS among Preservice Elementary Teachers. International Journal of Science Education, 24(8), 785-802.

Çepni, S., Ayvacı, H.Ş. \& Bacanak, A.(2006). Fen Eğitimine Yeni Bir Bakış: Fen Teknoloji-Toplum (3.Baskı). Trabzon: Celepler Matbaacilik.

Çıttır, T.(2003). Gazi Üniversitesi Mesleki Ĕ̆itim Fakültesi El Sanatları Eğitimi Bölümü Öğrencilerinin Devam Ettikleri Öğretmenlik Programlarına İlişkin Tutumları İle Akademik Başarıları Arasındaki İlişki. Yayınlanmış Yüksek Lisans Tezi, Ankara Gazi Üniversitesi Eğitim Bilimleri Enstitüsü.

Çoban, G. Ü., Ergin, Ö. (2008). İlköğretim Öğrencilerinin Bilimsel Bilgiye Yönelik Görüşlerini Belirleme Ölçeği. İlköğretim Online, 7(3), 706-716. 
Dilworth, C.(2006). The .Metaphysics of Science: An Account of Modern Science in terms of Principles, Laws and Theories (2nd ed.). The Netherlands: Springer.

Duschl, R.(1990). Restructuring Science Education. The Importance of Theories and Their Development. New York: Teachers College Press.

Ergin, D.Y.(1995). Ölçeklerde Geçerlik ve Güvenirlik. Marmara Üniversitesi Atatürk Ĕ̆itim Fakültesi Eğitim Bilimleri Dergisi, 7, 125-148.

Gauch, H.G.(2009). Science, Worldviews and Education. Science E Education, 18, 667-695.

Hocaoğlu, D.(1996). Bilim ve İnanç/Îmân Üzerine Felsefî Bir İrdeleme. Köprü Dergisi, 53, 58-89.

Karasar, N.(2002). Bilimsel Araştırma Yöntemi. Ankara: Nobel Yayın Dağıtım.

Kuhn, T.(1970). Logic of Discovery or Psychology of Research? In I. Lakatos \& A. Musgrave (Eds.), Criticism and The Growth of Knowledge (ss. 1-23). Cambridge: Cambridge University Press.

Lederman, N. G.(1992). Students' and Teachers' Conceptions of the Nature of Science: A Review of the Research. Journal of Research in Science Teaching,29, 331-359.

Lederman, N.G. (1998). The State of Science Education: Subject Matter without Content. Electronic Journal of Science Education, 3(2), 1-12.

Lederman, N.G., Wade, P.D. \& Bell, R.L.(1998). Assessing Understanding of the Nature of Science: A Historical Perspective. In W. F. McComas (Ed.), The Nature of Science in Science Education: Rationales and Strategies (ss. 331-350). Dordrecht: Kluwer Academic Publishers.

Lederman, N.G., Abd-El-Khalick, F., Bell, R.L. \& Schwartz, R.(2002). Views of nature of science questionnaire: Toward valid and meaningful assessment of learners' conceptions of nature of science. Journal of Research in Science Teaching, 39(6), 497-521.

Lederman, N.G.(2007). Nature of Science: Past, Present, and Future. In S. K. Abell, N. G. Lederman (Eds.), Handbook of Research on ScienceEducation (ss. 831-879). London: Lawrence Erlbaum Associates.

McComas, W.F.(1998). The Principal Elements of the Nature of Science: Dispeling the Myths. In W. F. McComas (Ed.), The Nature of Science in Science Education: Rationales and Strategies (ss. 53-70). Dordrecht: Kluwer Academic Publishers.

McComas, W.F., Clough, M.P. \& Almazroa, H.(1998). The Role And Character Of The Nature Of Science in Science Education.In W. F. McComas (Ed.), The Nature of Science in Science Education Rationales and Strategies (ss. 3-39). Dordrecht: Kluwer Academic Publishers.

Meichtry, Y.J.(1992). Influencing Student Understanding of the Nature of Science: Data From a Case of Curriculum Development. Journal of Reseach in Science Teaching, 29(4), 389-407.

Munby, H.(1982). “What Is Scientific Thinking?” A Discussion Paper, Ottawa: Science Council of Canada.

Murcia, K. \& Schibeci, R.(1999). Primary Student Teachers' Conceptions of the Nature of Science. International Journal of Science Education, 21 (11), 1123-1140.

Muşlu, G.(2008). İlköğretim 6. Sını Öğrencilerinin Bilimin Doğasın Sorgulama Düzeylerinin Tespiti Ve Çeşitli Etkinliklerle Geliştirilmesi. Yayınlanmış Doktora Tezi, Marmara Üniversitesi Eğitim Bilimleri Enstitüsü.

Palmquist, B. \& Finley, F.N.(1997). Preservice Teachers' Views of Nature of Science During a Postbaccalaureate Science Teaching Program. Journal of Research in Science Teaching, 34(6), 595-615.

Popper, K.(1998). The Rationality of Science Revolutions. In J. A. Kourany (Ed.), Scientific Knowledge (ss. 286-300). Wadsworth, CA: Belmont.

Rubba, P.A., \& Andersen H.O.(1978). Development of an Instrument to Assess Secondary Students' Understanding of the Nature of Scientific Knowledge. Science Education, 62, 449-458. 
Tavşancıl, E.(2005). Tutumların Ölçülmesi ve SPSS ile Veri Analizi. Ankara: Nobel Yayın Dağıtım.

Tezbaşaran, A.(1996). Likert Tipi Ölçek Geliştirme Kılavuzu. Ankara: Özyurt Matbaası.

Tsai, C.(1999). The Progression Toward Constructivist Epistemological Views of Science: A Case Study of the STS Instruction of Taiwanese High School Female Students. International Journal of Science Education, 21(11), 1201-1222.

Turgut, H.(2010). Assesing Preservice Science Teachers' Nature of Science Understandings: From Explicit to Tacit. XIV. IOSTE Symposium. Bled, Slovenia.

Turgut, H.(2011). The Context of Demarcation in Nature of Science Teaching: The Case of Astrology, Science \& Education, 20(5-6), 491-515.

Yıldırım, C.(2007). Bilim Felsefesi (11. Bask1). İstanbul: Remzi Kitabevi AŞ. 
EK: Bilimin Doğası İnanışları Ölçeği

\begin{tabular}{|c|c|c|c|c|c|}
\hline & 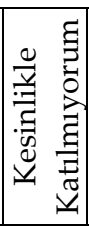 & 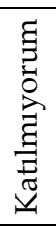 & 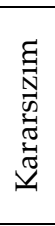 & 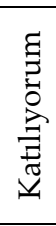 & 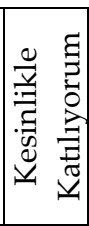 \\
\hline \multicolumn{6}{|l|}{ 1.Bir bilgi bilimsel ise kesin olarak kanıtlanmıştır ve artık değiş̧mez. } \\
\hline \multicolumn{6}{|l|}{$\begin{array}{l}\text { 2. "Serbest bıraktığım cisim yere düştü" diyen öğrenci, yaptığı bir } \\
\text { gözlemi ifade etmiş olur. }\end{array}$} \\
\hline \multicolumn{6}{|l|}{$\begin{array}{l}\text { 3. Bilim insanlarının basamaklarını sırasıyla takip ettikleri tek bir bi- } \\
\text { limsel yöntem vardır. }\end{array}$} \\
\hline \multicolumn{6}{|l|}{$\begin{array}{l}\text { 4.Bilim insanları, ellerindeki verilerden sonuca giderken yaratıcılıklarını } \\
\text { ve hayal güçlerini kullanırlar. }\end{array}$} \\
\hline \multicolumn{6}{|l|}{ 5.Bilim sadece doğrudan gözlenebilen olayları konu edinir. } \\
\hline \multicolumn{6}{|l|}{$\begin{array}{l}\text { 6.Bilim, toplumsal değerlere (politik, dini, felsefi vb.) bağımlıdır ve } \\
\text { gelişim sürecinde bu değerlerden etkilenir. }\end{array}$} \\
\hline \multicolumn{6}{|l|}{ 7.Bilim, doğanın işleyişinin anlaşılabileceği kabulüne dayanır. } \\
\hline \multicolumn{6}{|l|}{$\begin{array}{l}\text { 8.Bilimsel araştırmalar doğru yapılsalar bile, bu araştırmalar sonucunda } \\
\text { ulaşılan bilgiler gelecekte değişebilir. }\end{array}$} \\
\hline \multicolumn{6}{|l|}{ 9. Farklı bilim insanları aynı verilere sahipse aynı sonuca ulaşırlar. } \\
\hline \multicolumn{6}{|l|}{$\begin{array}{l}\text { 10.Bilimsel teoriler, doğrudan gözlenemeyen varlıklarla ilgili, belirli } \\
\text { varsayımlara dayalı açıklamalardır. }\end{array}$} \\
\hline \multicolumn{6}{|l|}{$\begin{array}{l}\text { 11.Bilimsel teoriler kanıtlanıp, bilim dünyası tarafından kabul } \\
\text { gördükten sonra bilimsel kanunlara dönüşüurler. }\end{array}$} \\
\hline \multicolumn{6}{|l|}{$\begin{array}{l}\text { 12.Bilim insanlarının çalışmalarında ulaştıkları sonuçlar üzerinde kiş̧isel } \\
\text { duygu ve düşüncelerinin bir etkisi yoktur. }\end{array}$} \\
\hline \multicolumn{6}{|l|}{$\begin{array}{l}\text { 13.Azot gazının sıkışma-genleşme özelliği olduğunu tespit eden } \\
\text { öğrenci, "Azot gazı boşluklu yapıdadır" dediğinde bir gözlemini ifade } \\
\text { etmiş olur. }\end{array}$} \\
\hline \multicolumn{6}{|l|}{ 14.Bilimsel kanunlar, kesin olarak ispatlanmış bilimsel iddialardır. } \\
\hline \multicolumn{6}{|l|}{$\begin{array}{l}\text { 15.Bilimsel deneylerle bir sonuca ulaşılmışsa, bu sonuç kesinlikle } \\
\text { doğrudur. }\end{array}$} \\
\hline \multicolumn{6}{|l|}{ 16.Bilim, insan yaşamıyla ilgili bütün sorulara cevap veremez. } \\
\hline \multicolumn{6}{|l|}{ 17.Bilimsel çalışmalarda yaratıcılık ve hayal gücü de kullanılır. } \\
\hline \multicolumn{6}{|l|}{$\begin{array}{l}\text { 18.Bilimsel çalışmalar, toplumların kültürlerinden ve değer yargıların- } \\
\text { dan etkilenir. }\end{array}$} \\
\hline \multicolumn{6}{|l|}{ 19.Farklı bilim dallarında farklı bilimsel yöntemler kullanılır. } \\
\hline \multicolumn{6}{|l|}{$\begin{array}{l}\text { 20.Bilim insanları geliştirdikleri hücre teorisinden artık kesin olarak } \\
\text { emindirler. }\end{array}$} \\
\hline \multicolumn{6}{|l|}{$\begin{array}{l}\text { 21.Serbest bıraktığı cismin "Yerçekimi kuvveti yüzünden düştüğünü" } \\
\text { söyleyen öğrenci bir gözlemini ifade etmiş olur. }\end{array}$} \\
\hline \multicolumn{6}{|l|}{ 22.Doğrudan deney konusu yapılamayan bir iddia, bilimsel olamaz. } \\
\hline \multicolumn{6}{|l|}{$\begin{array}{l}\text { 23. Yeni bilimsel teoriler ortaya atıldıkça bilim insanları ellerindeki ver- } \\
\text { ileri yeniden yorumlayarak iddialarını_değiştirebilirler. }\end{array}$} \\
\hline \multicolumn{6}{|l|}{$\begin{array}{l}\text { 24.Bilim insanları yaratıcılıklarını ve hayal güçlerini sadece deneylerini } \\
\text { tasarlarken kullanırlar. }\end{array}$} \\
\hline \multicolumn{6}{|l|}{$\begin{array}{l}\text { 25.“Metal bir kaşığı 1sı kaynağına tuttuğunda ısındığını” söyleyen } \\
\text { öğrenci bir gözlemini ifade etmiş olur. }\end{array}$} \\
\hline $\begin{array}{l}\text { 26.Bilim, bilimsel kanunların evrenin her yerinde aynı şekilde geçerli } \\
\text { olduğu kabulüne dayanır. }\end{array}$ & & & & & \\
\hline
\end{tabular}




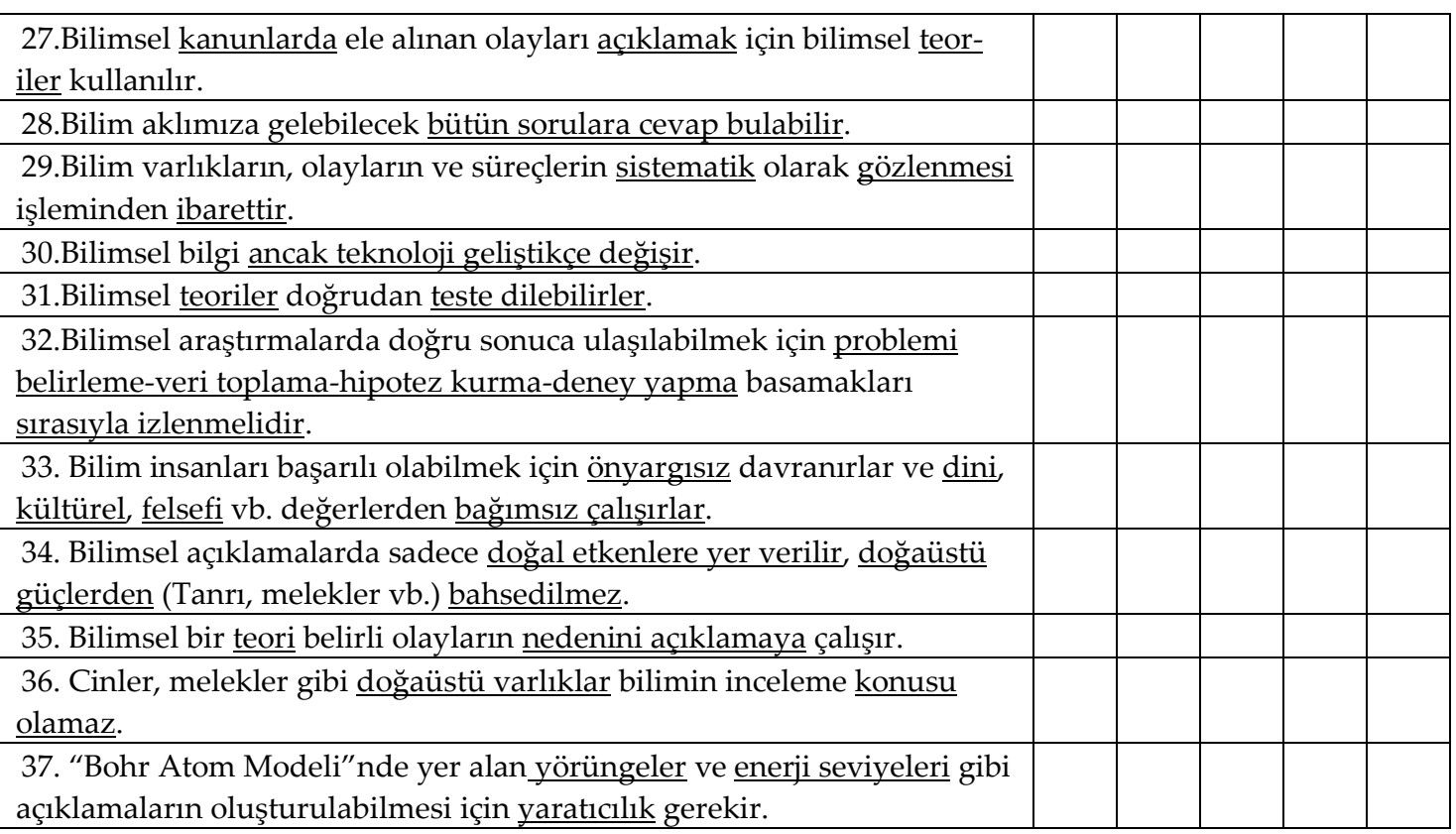




\section{Extended Summary}

\section{Introduction}

One of the most important aims of current science education is to educate individuals as scientifically literate (Murcia \& Schibeci, 1999; Tsai, 1999; Abd-El-Khalick \& Lederman, 2000) and this aim directs educators of science also to methodological and epistemological value of knowledge instead of just teaching of it. Such a perspective became dominant in Turkey with recent educational reform movements and while underlying the concept of scientific literacy it also requires focusing on nature of science (NOS). So developing the nature of science understandings of individuals became crucial. However the results of previous researches concerned with improving students' understanding of the NOS indicated that students from various age groups and even teachers possess both inaccurate and inappropriate views of NOS (Lederman, 1992; Duschl, 1990; Abd-El-Khalick, \& Lederman, 2000). Such a failure had explained by the help of the view that perceptions about the NOS are well assimilated into mental structures and resistant to change (Meichtry, 1992). Hence, any expected development in the NOS understandings firstly requires the exposing of the current perceptions to challenge or alter and this issue addresses the effective assessment of NOS understandings which still remains equivocal (Lederman, Wade, \& Bell, 1998; Craven, Hand \& Prain, 2002).

In fact the issue of effective assessment of NOS understandings is critically discussed in related literature and current assessment instruments are evaluated in detail both for their strong and weak aspects (Craven, Hand \& Prain, 2002). However, this issue is oversimplified in Turkey to the problem of choosing an assessment instrument for adapting to Turkish in order to use in research. Since, the NOS literature developed in Turkish and research performed are still inadequate and most of the researchers prefer the assessment instruments developed in various cultures in order to assess NOS understandings. But, such an adopting process of any assessment instrument which developed in a foreign language involves some potential problems, especially if beliefs and understandings are questioned. So it seems obvious that, development of an assessment instrument for NOS understandings directly in Turkish is crucial which also requires the determination of a theoretical frame since researchers do not appear to share a common conception about of the NOS.

Generally, in related literature, NOS is often seen to be used to refer to both the epistemology and sociology of science as a way of knowing including the values, beliefs inherent to scientific knowledge (Lederman, 1992). Such a perspective underlines some sub-dimensions such as; (i) tentativeness, (ii) observation and inference, (iii) scientific method/methods, (iv) creativity and imagination, (v) socio-cultural embeddedness, (vi) scientific theories and laws; (vii) assumptions and boundaries of science (Abd-El Khalick, 2001; Lederman, Abd-El-Khalick, Bell \& Schwartz, 2002; McComas, 1998; AAAS, 1993; Chalmers, 1999; Hocaoğlu, 1996; Gauch 2009). Without ignoring the philosophical debates these aspects mentioned in many documents should be claimed to establish an acceptable theoretical frame for the NOS.

\section{Purpose of the Study}

In this research, the development of a likert-type Turkish assessment instrument called "Nature of Science Beliefs Scale (NSBS)" is aimed in order to expose the NOS understandings of preservice science teachers based on above sub-dimensions. The type of the instrument was decided as likert since it is easier to apply and analyze and cost effective although has some limitations such as being totally constructed. 


\section{METHODOLOGY}

In this section the development process of the NSBS is presented below from the stage of item writing to validity and reliability analysis.

\section{Development of Item Pool and Pilot Study}

The initial item pool for NSBS was established according to the sub-dimensions of NOS mentioned above. In this process, some of the items were derived from similar instruments developed before by various researchers (such as Rubba \& Andersen, 1978; Aikenhead \& Ryan 1992; Lederman, Abd-ElKhalick, Bell \& Schwartz, 2002; Muşlu, 2008; Can, 2008) and some of the items were written originally. In the initial item pool there were totally 49 items and they were evaluated by a team of experts involving three science educators and a science teacher for their content validity and language. In this first step some of the items were revised and some of them were canceled according to the views of experts. The revised form included 42 items and used in pilot study in order to see if participants will have any possible problems with the items. In the pilot study 47 participants answered the form and with the help of their feedbacks the NSBS had its form for validity and reliability analysis.

\section{Validity and Reliability Analysis of NSBS}

The form of NSBS developed after pilot study was applied to 390 preservice science teachers from two universities in Istanbul. However the validity and reliability analysis of the results were performed for 364 participants since the rest of them either did not completed the form or responded randomly (e.g. rated all the items as 5 or 1 ). The frequency and percentage distributions of the participants according to their class level are given below in Table 1.

Table 1. Frequency and Percentage Distribution

\begin{tabular}{lll}
\hline Class Level & $\mathrm{f}$ & $\%$ \\
\hline 1 & 120 & 32,96 \\
2 & 75 & 20,60 \\
3 & 85 & 23,35 \\
4 & 84 & 23,07 \\
Total & 364 & 100,0 \\
\hline
\end{tabular}

After the participants responds to NSBS rated, the analysis began initially for construct validity. At first the size of the sample which scale was applied questioned and Kaiser Meyer-Olkin value was calculated. It was found to be 0,74 which meant the sample size was adequate (see Akgül and Çevik, 2003; Büyüköztürk, 2010) and the process continued with confirmatory factor analysis since the theoretical frame and sub-dimensions of the scale were pre-determined. In the analysis process, the items which had factor loads greater then 0,30 and had a difference greater then 0,10 between factor loads if took place under more than one factor were considered (Büyüköztürk 2010, Tezbaşaran, 1996). It was seen that 37 of 42 items grouped under 7 factors according to this criteria and they were numbered again. The remaining items and their distribution to related factors (with the factor loads) are given below in Table 2.

Table 2. Confirmatory Factor Analysis Results of NSBS

\begin{tabular}{lll}
\hline Factors & Items & Factor Loads \\
\hline Tentativeness & $1,8,15,20,23,30$ & $0,543-0,779$ \\
Observation and Inference & $2,13,21,25$ & $0,688-0,741$ \\
Scientific Method/Methods & $3,19,29,32$ & $0,761-0,818$ \\
Creativity and Imagination & $4,9,17,24,37$ & $0,337-0,737$ \\
\hline
\end{tabular}




\begin{tabular}{llll}
\hline $\begin{array}{l}\text { Assumptions and } \\
\text { ries }\end{array}$ & Bounda- & $5,7,16,22,26,28,34,36$ & $0,413-0,704$ \\
$\begin{array}{l}\text { Socio-cultural } \\
\text { dedness }\end{array}$ & Embed- & $6,12,18,33$ & $0,605-0,746$ \\
\begin{tabular}{l} 
Theories and Laws \\
\hline
\end{tabular} & $10,11,14,27,31,35$ & $0,395-0,649$ \\
\hline
\end{tabular}

The factor analysis was followed by reliability analysis since the sub-dimensions (factors) of NSBS were determined. In this process the item-total correlations and Cronbach-Alpha values (Balc1, 2001; Ergin, 1995) were calculated. The values and results derived are given below in Table 3.

Table 3. Item-total Correlations and Cronbach-Alfa Values of NSBS

\begin{tabular}{lllll}
\hline Factors & Items & $\mathrm{r}$ & $\mathrm{p}$ & $\alpha$ \\
\hline Tentativeness & $1,8,15,20,23,30$ & $0,330-0,765$ & 0,000 & 0,803 \\
\hline Observation and Inference & $2,13,21,25$ & $0,510-0,690$ & 0,000 & 0,704 \\
\hline Scientific Method/Methods & $3,19,29,32$ & $0,380-0,676$ & 0,000 & 0,829 \\
\hline Creativity and Imagination & $4,9,17,24,37$ & $0,370-0,757$ & 0,000 & 0,705 \\
\hline Assumptions and Boundaries & $\begin{array}{l}5,7,16,22,26,28, \\
\text { Socio-cultural Embeddedness }\end{array}$ & $\begin{array}{l}0,398-0,690 \\
\text { (3, 12, 18, 33 }\end{array}$ & 0,000 & 0,764 \\
\hline Theories and Laws & $10,11,14,27,31$, & $0,397-0,876$ & 0,000 & 0,732 \\
\hline
\end{tabular}

The results given in Table 3 showed that both the item-total correlations and Cronbach-Alfa values $(0,783$ for the whole scale) of scale are meaningful for all the factors and NSBS is seen to be reliable.

\section{DISCUSSION and RESULTS}

The need for an effective instrument which can be used commonly in order to assess the NOS understandings of preservice science teachers that developed in Turkish is obvious. This claim can be understood easily with a quick search in dissertations issued the NOS understandings in Turkey. Because, such a quick search shows that almost all the researchers used adopted instruments from other languages/cultures in their research and preferred especially VOSTS (Aikenhead \& Ryan, 1992) and VNOS (Lederman, Abd-El-Khalick, Bell, Schwartz, 2002). However applying these instruments to large groups are hard and the analysis process of collected data requires expertise. The NSBS which developed in Turkish in this study with its extensive sub-dimensions/factors is seen to meet this need. Especially, its factor of "assumptions and boundaries" of science which do not commonly exists in current instruments and the other six factors which discussed widely in related literature under the concept of NOS make NSBS comprehensive. In addition to its inclusive factor structure, also the results of validity and reliability analysis performed were also showed that NSBS is a qualified instrument which can be applied to large groups. So, NSBS is assumed to be used easily and commonly in Turkey with taking into consideration the limitations of likert type instruments.

\section{SUGGESTIONS}

The NSBS developed in this study have some limitations since it is likert type and hence the attempts to assess the NOS understandings more effectively and comprehensively in Turkish must be continued. Some open ended new instruments can be developed in order to have the chance of deeper examination of the NOS understandings which can be used in coordination with NSBS. In such an assessment process NSBS can be applied to large groups at first step and open ended instruments can be applied to representative participants who are determined according to the results of NSBS at next step for deeper analysis. An interview protocol which will be based on the factors/sub-dimensions of NSBS may be a good start. 